\title{
Efficacy of anti-PD-1 antibodies in NSCLC patients with an EGFR mutation and high PD-L1 expression
}

\author{
Ken Masuda ${ }^{1} \cdot$ Hidehito Horinouchi ${ }^{1}$ (1) $\cdot$ Midori Tanaka $^{1} \cdot$ Ryoko Higashiyama $^{1} \cdot$ Yuki Shinno $^{1} \cdot$ Jun Sato ${ }^{2}$. \\ Yuji Matsumoto $^{1} \cdot$ Yusuke Okuma $^{1} \cdot$ Tatsuya Yoshida $^{1} \cdot$ Yasushi Goto $^{1} \cdot$ Noboru Yamamoto $^{1,2} \cdot$ Yuichiro Ohe $^{1}$
}

Received: 8 June 2020 / Accepted: 18 July 2020 / Published online: 23 July 2020

(C) The Author(s) 2020

\begin{abstract}
Introduction Several studies have demonstrated that non-small cell lung cancer patients (NSCLCs) harboring epidermal growth factor receptor $(E G F R)$ mutations have poor clinical outcomes in response to treatment with programmed death-1 (PD-1) inhibitors. However, it remains unclear whether EGFR-mutated NSCLCs with a high programmed death-ligand-1 (PD-L1) expression (tumor proportion score $\geq 50 \%$ ) respond to PD-1 inhibitors.

Methods We retrospectively investigated the NSCLCs who had received PD-1 inhibitors between January 2016 and December 2018 to assess the efficacy of PD-1 inhibitors in patients with an EGFR mutation and high PD-L1 expression.

Results There were 153 patients with a high PD-L1 expression level, and the median progression-free survival (mPFS) was 5.3 months [95\% confidence interval (CI) 1.3-12.4 months] in the patients with EGFR mutations $(n=17)$ and 8.3 months (95\% CI 6.0-11.7 months) in those with wild-type EGFR ( $n=136$; hazard ratio (HR) 1.62; 95\% CI 0.83-2.87). Among the 110 patients in the low PD-L1 expression group, the mPFS was 1.6 months (95\% CI 1.3-5.9 months) in the patients with EGFR mutations $(n=18)$ and 3.8 months (95\% CI 2.5-5.9 months) in those with wild-type EGFR $(n=92$; HR 2.59 ; $95 \%$ CI 1.48-4.31). The HR for PFS in the group with EGFR mutations and high PD-L1 expression was 0.97 (95\% CI 0.56-1.59) compared to the group with wild-type EGFR and low PD-L1 expression.

Conclusions PD-1 inhibitors can serve as one of the treatment options for NSCLCs with an EGFR mutation and high PD-L1 expression.
\end{abstract}

Keywords Non-small cell lung cancer · Programmed death-ligand-1 · Epidermal growth factor receptor · Immune checkpoint inhibitor

\section{Introduction}

Immune checkpoint inhibitors (ICIs), particularly inhibitors of the programmed death-1 (PD-1) axis, have revolutionized the treatment of non-small cell lung cancer (NSCLC). Treatment with ICIs has been shown to result in a significant tumor response and overall survival (OS) benefit in advanced NSCLC (Borghaei et al. 2015; Brahmer et al. 2015; Mok et al. 2019; Reck et al. 2016). Programmed death-ligand-1 (PD-L1) expression in tumor

Hidehito Horinouchi

hhorinou@ncc.go.jp

1 Department of Thoracic Oncology, National Cancer Center Hospital, 5-1-1 Tsukiji, Chuo-ku, Tokyo 104-0045, Japan

2 Department of Experimental Therapeutics, National Cancer Center Hospital, Tokyo, Japan cells is associated with improved clinical outcomes of PD-1 pathway blockade in NSCLC patients (Garon et al. 2015; Herbst et al. 2014). Pembrolizumab monotherapy has become a standard first-line treatment for advanced NSCLC in patients with a PD-L1 tumor proportion score (TPS) of at least $50 \%$, based on the results of the KEYNOTE-024 phase III trial (Reck et al. 2016). Several studies have also shown a relationship between high PD-L1 expression and a higher objective response rate (ORR) and better survival in NSCLC patients treated with PD-1 inhibitors, including nivolumab and pembrolizumab (Aguiar et al. 2017). However, most clinical studies have excluded specific patients, for example, patients with epidermal growth factor receptor $(E G F R)$ mutations.

Several studies have reported disappointing clinical outcomes with lower response rates and shorter survival in patients with EGFR-mutated NSCLC treated with PD-1 
inhibitors than in patients with EGFR-wild NSCLC (Bylicki et al. 2017; Gainor et al. 2016; Lee et al. 2018; Santambrogio and Rammensee 2019). EGFR tyrosine kinase inhibitors (EGFR-TKIs) are standard first-line treatment for EGFR-mutated NSCLC. Lisberg et al. reported a phase II trial of pembrolizumab in TKI-naive patients with advanced EGFR-mutated, PD-L1-positive NSCLC and concluded that pembrolizumab is not appropriate as a first-line treatment for EGFR-mutated NSCLC before EGFR-TKI therapy (Lisberg et al. 2018). However, it remained unclear whether EGFRmutated NSCLC with high PD-L1 expression (TPS $\geq 50 \%$ ) responds to ICIs, because the sample size in their trial was too small. We retrospectively investigated the relationship between PD-L1 expression and the efficacy of PD-1 inhibitors in NSCLC patients to assess the efficacy of PD-1 inhibitors in patients with an EGFR mutation and high PD-L1 expression.

\section{Materials and methods}

\section{Study design}

This study was a retrospective, single-center, observational study conducted at the National Cancer Center Hospital in Japan. The study was approved by the Institutional Review Board of the National Cancer Center Hospital (No. 2015-355).

\section{Subjects}

Patients with advanced NSCLC who had been treated with an anti-PD-1 antibody between March 2017 and December 2018 at the National Cancer Center Hospital in Japan were identified from the database. Patients with no PD-L1 expression data were excluded. We reviewed the medical records and abstracted the following patient characteristics: age, gender, Eastern Cooperative Oncology Group Performance Status (ECOG-PS), histology, disease status, EGFR mutation status, details of treatment, and survival. PD-L1 expression was evaluated using the PD-L1 22C3 pharmDx (Dako, Carpinteria, CA, USA) and EGFR mutations were identified using the Cobas® EGFR Mutation Test v2 (Cobas; Roche Diagnostics, Basel, Switzerland). The patients who were adopted as subjects of our study were divided into four groups according to PD-L1 expression level and EGFR mutation status. In our study, low PD-L1 expression was defined as the presence of $<50 \%$ positive-staining tumor cells, whereas $\geq 50 \%$ positive staining was considered high PD-L1 expression. The efficacy of treatment with the PD-1 inhibitors in the four groups was assessed by evaluating progression-free survival (PFS).

\section{Treatment and assessment}

In the safety analysis, we evaluated adverse events associated with ICIs or EGFR-TKIs according to the National Cancer Institute Common Terminology Criteria for Adverse Events, version 4.03. Objective tumor response in patients with target lesions was evaluated based on the Response Evaluation Criteria in Solid Tumors version 1.1 and assessment by computed tomography every $6-8$ weeks after the start of treatment.

\section{Statistical analysis}

Differences between groups were analyzed using Fisher's exact test for categorical variables. PFS was defined as the time between the start of PD-1 inhibitor treatment and progression or death from any cause; PFS was censored at a date when the patient was confirmed to be progression free. Patients whose treatment was discontinued due to toxicity in the absence of disease progression were censored at the start of the next treatment. Overall survival (OS) was measured until death or censored at the latest follow-up examination of surviving patients. Survival rates were estimated by the Kaplan-Meier method and compared using the log-rank test. All statistical analyses were performed using the JMP version 14.0 software program (SAS Institute, Cary, NC, USA). All $P$ values were two sided, and $p<0.05$ was considered evidence of a statistically significant difference.

\section{Results}

\section{Patient characteristics}

In this study, the 414 NSCLC patients treated with nivolumab or pembrolizumab at the National Cancer Center Hospital between March 2017 and December 2018 were identified as candidates for inclusion, and 263 of them were ultimately adopted as subjects of our study. We excluded 151 patients for the following reasons: absence of PD-L1 data $(n=125)$, participation in a clinical trial of pembrolizumab or nivolumab $(n=22)$, and NSCLC with $A L K$ rearrangement $(n=4)$ (Fig. 1). The median age of the subjects was 62 years (range 33-87 years). High PD-L1 expression was found in 153 patients (58.2\%). Thirty-five (7.5\%) patients had EGFR mutations, and 29 (82.9\%) of these 35 patients had an exon 19 deletion or exon 21 L858R mutation (Table 1). 
414 patients, advanced NSCLC, received $\mathrm{PD}-1$ inhibitors

January 2016 - December 2018 in $\mathrm{NCCH}$

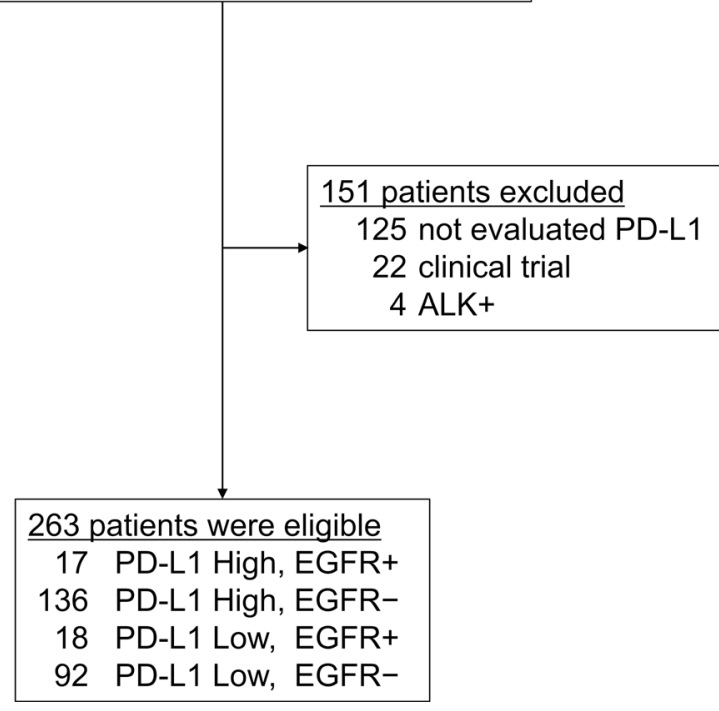

Fig. 1 Patient selection. Of the 414 non-small cell lung cancer (NSCLC) patients treated with nivolumab or pembrolizumab at the National Cancer Center Hospital in Japan between March 2017 and December 2018, the 263 patients were adopted as the subjects of this study and divided into 4 groups based on their programmed death-ligand-1 (PD-L1) expression level and EGFR mutation status. The reasons for excluding 151 patients were absence of PD-L1 data $(n=125)$, participation in a clinical trial of pembrolizumab or nivolumab $(n=22)$, and NSCLC with $A L K$ rearrangement $(n=4)$

\section{Efficacy}

The median follow-up time was 11.3 months [95\% confidence interval (CI) 9.0-14.7 months]. Table 2 summarizes the efficacy of the PD-1 inhibitors. Kaplan-Meier curves for PFS according to PD-L1 expression level and EGFR mutation status are shown in Fig. 2. In the high PD-L1 expression group, the ORR was $29.4 \%$ (95\% CI $1.3-53.1 \%)$ in the EGFR mutation subgroup $(n=17)$ and $43.4 \%$ (95\% CI $35.4-51.8 \%$ ) in the wild-type $E G F R$ subgroup $(n=136)$. Median PFS was 5.3 months $(95 \%$ CI 1.3-12.4 months) in the EGFR mutation subgroup and 8.3 months (95\% CI 6.0-11.7 months) in the wildtype EGFR subgroup [hazard ratio (HR) $1.62 ; 95 \% \mathrm{CI}$ $0.83-2.87 ; p=0.125]$. In the low PD-L1 expression group, the ORR was $0 \%$ in the EGFR mutation subgroup $(n=18)$ and $16.3 \%$ (95\% CI 10.1-25.2\%) in the wild-type $E G F R$ subgroup $(n=92)$. Median PFS was 1.6 months (95\% CI 1.3-2.5 months) in the EGFR mutation subgroup and 3.8 months (95\% CI 2.5-5.9 months) in the wild-type EGFR subgroup (HR 0.39; 95\% CI 0.23-0.66; $p<0.001$ ). The PFS of the group with EGFR mutations and high PD-L1 expression was similar to the PFS in the group with wild-type $E F G R$ and low PD-L1 expression (HR 0.97; 95\% CI $0.56-1.59 ; p=0.909)$. In the $E G F R$ mutation group, median OS was 26.4 months (95\% CI, 6.7 to not evaluated) in the high PD-L1 expression subgroup and 12.7 months (95\% CI 2.6 to not evaluated) in the low PD-L1 expression subgroup. In the wild-type EGFR group, median OS was 36.2 months (95\% CI 21.0-36.2 months) in the high PD-L1 expression subgroup and 13.0 months (95\% CI 9.9-29.7 months) in the low PD-L1 expression subgroup. Regarding the patterns of progression after PD-1 inhibitors, there was no significant difference between the EGFR mutation group and the wild-type EGFR group.

\section{Toxicity}

An immune-related adverse event (irAE) developed in 5 (29.4\%) of the 17 patients with EGFR-mutated NSCLC and high PD-L1 expression. The most frequent adverse events in this study were diarrhea $(n=2)$ and hypothyroidism $(n=2)$. Grade 3 alanine and aspartate aminotransferase elevation was observed in one patient. Grade 4 small intestinal perforation occurred in one patient treated with nivolumab, and nivolumab was discontinued; however, PD-1 inhibitor therapy was continued after the irAE in the other patients. There were no grade 5 adverse events related to the PD- 1 inhibitors.

\section{Discussion}

The results of our study showed that PD-L1 expression was associated with the efficacy of PD-1 inhibitors in patients with EGFR mutations. The ORR and median PFS in the high PD-L1 expression group were 29.4\% (95\% CI 1.3-53.1\%) and 5.3 months (95\% CI 1.3-12.4 months), respectively, compared with $0 \%$ and 1.6 months (95\% CI 1.3-2.5 months), respectively, in the low PD-L1 expression group. In the group of patients with an EGFR mutation, the efficacy of the PD-1 inhibitors was greater in the subgroup of patients with high PD-L1 expression than in the subgroup with low PD-L1 expression. Moreover, PFS in the group with EGFR mutations and high PD-L1 expression was similar to PFS in the group with wild-type EFGR and low PD-L1 expression (HR 0.97; 95\% CI 0.56-1.59; $p=0.909$ ).

Berghoff et al. recently reviewed ICI treatment in patients with oncogene-addicted NSCLC (Berghoff et al. 2019). They evaluated the efficacy of ICIs in NSCLC patients with wild-type EGFR and in patients with EGFR-mutated NSCLC in five clinical trials: CheckMate 057 (Borghaei et al. 2015), KEYNOTE-010 (Herbst et al. 2016), OAK (Rittmeyer et al. 2017), POPLAR (Fehrenbacher et al. 2016), and IMpower150 (Socinski et al. 2018), and found that the survival benefits of treatment with an ICI tended to 
Table 1 Patient characteristics

\begin{tabular}{|c|c|c|c|c|c|}
\hline & All patients $N$ & PD-L1 high EGFR $+N$ & PD-L1 high EGFR $-N$ & PD-L1 low EGFR $+N$ & PD-L1 low EGFR $-N$ \\
\hline Total $N$ & 263 & 17 & 136 & 18 & 92 \\
\hline Median age, years (range) & $62(33-87)$ & $62(47-85)$ & $62(33-87)$ & $64.5(37-83)$ & $62(33-83)$ \\
\hline \multicolumn{6}{|l|}{ Sex } \\
\hline Female & 83 & 7 & 36 & 15 & 25 \\
\hline Male & 180 & 10 & 100 & 3 & 67 \\
\hline \multicolumn{6}{|l|}{ ECOG-PS } \\
\hline 0,1 & 236 & 14 & 125 & 16 & 81 \\
\hline 2 & 27 & 3 & 11 & 2 & 11 \\
\hline \multicolumn{6}{|l|}{ Smoking history } \\
\hline Never smoker & 53 & 7 & 21 & 12 & 13 \\
\hline Smoker & 210 & 10 & 115 & 6 & 79 \\
\hline \multicolumn{6}{|l|}{ Histologic classification } \\
\hline Adenocarcinoma & 203 & 16 & 107 & 18 & 62 \\
\hline Squamous & 52 & 0 & 24 & 0 & 28 \\
\hline Others & 8 & 1 & 5 & 0 & 2 \\
\hline \multicolumn{6}{|l|}{ Disease status } \\
\hline Stage IV & 140 & 9 & 75 & 12 & 44 \\
\hline Stage III & 53 & 3 & 30 & 2 & 18 \\
\hline Recurrence & 70 & 5 & 31 & 4 & 30 \\
\hline \multicolumn{6}{|l|}{ EGFR mutation status } \\
\hline Ex19del & 21 & 8 & 0 & 13 & 0 \\
\hline L858R & 8 & 6 & 0 & 2 & 0 \\
\hline Others & 6 & 3 & 0 & 3 & 0 \\
\hline Negative & 0 & 0 & 136 & 0 & 92 \\
\hline \multicolumn{6}{|l|}{ ICIs status } \\
\hline Pembrolizumab & 141 & 11 & 105 & 4 & 21 \\
\hline Nivolumab & 122 & 6 & 31 & 14 & 71 \\
\hline \multicolumn{6}{|l|}{ Line of ICI } \\
\hline First-line & 92 & 2 & 85 & 0 & 5 \\
\hline Second-line & 111 & 3 & 42 & 2 & 64 \\
\hline Third-line or more & 60 & 12 & 9 & 16 & 23 \\
\hline
\end{tabular}

ECOG-PS Eastern Cooperative Oncology Group Performance Status, EGFR epidermal growth factor receptor, ICI immune checkpoint inhibitors, $P D-L 1$ programmed death-ligand 1

Table 2 Summary of the efficacy of PD-1 inhibitors

\begin{tabular}{llll}
\hline & ORR (\%) 95\% CI & $\begin{array}{l}\text { mPFS (month) } \\
95 \% \text { CI }\end{array}$ & HR of mPFS 95\% CI \\
\hline PD-L1 high EGFR $-N=136$ & 43.4 & 8.3 & 0.56 \\
& $35.4-51.8$ & $6.0-11.7$ & $0.40-0.78$ \\
PD-L1 high EGFR $+N=17$ & 29.4 & 5.3 & 0.97 \\
& $1.3-53.1$ & $1.3-12.4$ & $0.56-1.59$ \\
PD-L1 low EGFR $-N=92$ & 16.3 & 3.8 & Reference \\
PD-L1 low EGFR $-N=18$ & $10.1-25.2$ & 2.5 to 5.9 & \\
& 0 & 1.6 & 2.59 \\
& & $1.3-2.5$ & $1.48-4.31$ \\
\hline
\end{tabular}

$C I$ confidence interval, EGFR epidermal growth factor receptor, $H R$ hazard ratio, $m P F S$ median progression-free survival, $O R R$ objective response rate, $P D-L 1$ programmed death-ligand 1

be lower in patients with EGFR mutations than in patients with wild-type EGFR. Lee et al. performed a meta-analysis study that assessed the role of ICIs as second-line therapy in advanced EGFR-mutated NSCLC (Lee et al. 2018). Their analysis of the data from three clinical trials (CheckMate 057 (Borghaei et al. 2015), KEYNOTE-010 (Herbst et al. 
Fig. 2 Kaplan-Meier curve for progression-free survival (PFS) according to PD-L1 expression and EGFR mutation status. In the high PD-L1 expression group, median PFS was 5.3 months (95\% CI 1.3-12.4 months) in the EGFR mutation subgroup and 8.3 months $(95 \% \mathrm{CI}$ $6.0-11.7$ months) in the wildtype EGFR subgroup. In the low PD-L1 expression group, median PFS was 1.6 months (95\% CI 1.3-2.5 months) in the EGFR mutation subgroup and 3.8 months (95\% CI 2.5 5.9 months) in the wild-type EGFR subgroup

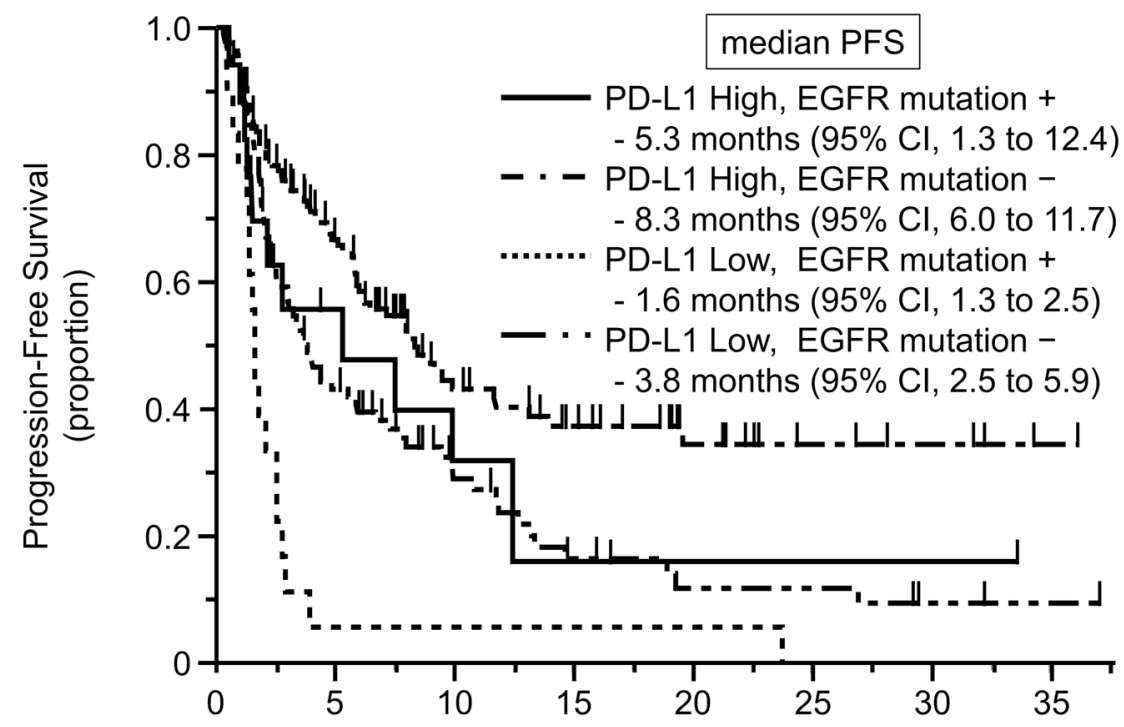

No. at risk

PD-L1 High,EGFR+ 17

PD-L1 High, EGFR- 136

PD-L1 Low, EGFR+ 18

PD-L1 Low, EGFR- 92

$\begin{array}{cc}7 & 4 \\ 74 & 32 \\ 1 & 1 \\ 37 & 17\end{array}$

Time (month)

$\begin{array}{ccccc}2 & 1 & 1 & 1 & 0 \\ 22 & 12 & 7 & 4 & 1 \\ 1 & 1 & 0 & 0 & 0 \\ 8 & 5 & 5 & 2 & 1\end{array}$

2016), and POPLAR (Fehrenbacher et al. 2016)) showed that ICIs did not improve OS compared with docetaxel therapy. Both meta-analyses also evaluated the results of ICI therapy in PD-L1-positive NSCLC, but there have been no reports on the efficacy of ICIs in patients with EGFRmutated NSCLC and high PD-L1 expression. Our own data showed that PD-1 inhibitors were beneficial as second-line or later treatment of patients with EGFR-mutated NSCLC and high PD-L1 expression.

Data regarding the relative risk of toxicity with ICIs and EGFR-TKIs in NSCLC patients in several studies have revealed more severe irAEs when EGFR-TKIs were used in combination with ICIs or used after ICIs. Ahn et al. reported that a phase Ib clinical trial of concurrent durvalumab (antiPD-L1 agent) plus osimertinib was halted due to a high rate of interstitial lung disease (Ahn et al. 2016). Schoenfeld et al. found that treatment with an ICI followed by osimertinib was associated with severe irAEs (Schoenfeld et al. 2019), but no irAEs were observed in their study when osimertinib preceded ICI therapy or when treatment with an ICI was followed by other EGFR-TKIs. A case reported by Kaira et al. showed that EGFR-TKI re-challenge immediately after nivolumab therapy may be tolerable and effective in patients with EGFR-TKI resistance (Kaira and Kagamu 2019). Whether irAEs are more severe when EGFR-TKIs are used in combination with ICIs or after ICIs remains a matter of controversy. If future investigations elucidate the mechanisms of toxicity and clinical situations in which toxicity develops, it might be possible to provide better treatment options and clinical benefits to patients with EGFR-mutated NSCLC and high PD-L1 expression.

This study had several limitations. First, this study was retrospective and conducted in a single center. The followup periods were not identical; however, all patients were regularly followed up every 1-2 months as outpatients, and evaluations were performed every 3-6 months for 1 year. In addition, their condition was subsequently checked every 6 months by X-ray, computed tomography (CT), magnetic resonance imaging, or positron emission tomography $\mathrm{CT}$. Second, patient characteristics were not uniform across the groups, and that may have led to selection bias.

\section{Conclusions}

In conclusion, our study showed that patients with EGFRmutated NSCLC and higher PD-L1 expression received a greater benefit of treatment with PD-1 inhibitors in terms of ORR and PFS than patients with low PD-L1 expression did. In addition, the ORR and PFS in the group of NSCLC patients with an EGFR mutation and high PD-L1 expression were similar to the ORR and PFS in the group with wildtype EFGR and low PD-L1 expression. The findings in our study suggest that even in NSCLC patients with an EGFR mutation evaluation of PD-L1 expression can help predict the efficacy of PD-1 inhibitors, and that PD-1 inhibitors can serve as one of the treatment options for patients with an EGFR mutation and high PD-L1 expression. 
Acknowledgements We greatly appreciate the participation of the patients and their families and the assistance of the staff of the Department of Thoracic Oncology and Experimental Therapeutics of the National Cancer Center Hospital.

Author contributions $\mathrm{KM}$ and $\mathrm{HH}$ made contributions to the conception and design, acquisition of data, and data analysis. KM drafted the manuscript. HH made substantial contributions to the study design and revision of the manuscript. KM analyzed and interpreted data and edited the manuscript. All authors critically reviewed the manuscript, and all approved the final version submitted for publication.

Funding The authors declare that this study was not funded.

Data availability The datasets generated during the current study are not publicly available due to ethical restrictions, but are available from the corresponding author on reasonable request.

\section{Compliance with ethical standards}

Conflict of interest Dr. Ohe reports grants and personal fees from Ono Pharmaceutical, grants and personal fees from Bristol-Myers Squibb, grants and personal fees from MSD, during the conduct of the study; grants and personal fees from AstraZeneca, personal fees from Boehringer Ingelheim, grants and personal fees from Chugai, grants and personal fees from Eli Lilly, grants and personal fees from Taiho, grants and personal fees from Takeda, grants and personal fees from Nippon Kayaku, grants and personal fees from Kyorin, grants and personal fees from Novartis, grants and personal fees from Janssen, personal fees from Pfizer, grants from Ignyta, grants from Kyowa Hakko Kirin, personal fees from Celtrion, personal fees from Amgen. Dr. Yamamoto reports grants from Chugai, grants from Taiho, grants from Eisai, grants from Lilly, grants from Quintiles, grants from Astellas, grants from BMS, grants from Novartis, grants from Daiichi-Sankyo, grants from Pfizer, grants from Boehringer Ingelheim, grants from Kyowa-Hakko Kirin, grants from Bayer, grants from ONO PHARMACEUTICAL CO., LTD, grants from Takeda, personal fees from ONO PHARMACEUTICAL CO., LTD, personal fees from Chugai, personal fees from AstraZeneca, personal fees from Pfizer, personal fees from Lilly, personal fees from BMS, personal fees from Eisai, personal fees from Otsuka, personal fees from Takeda, personal fees from Boehringer Ingelheim, personal fees from Cimic, grants from Janssen Pharma, grants from MSD, grants from Merck, personal fees from Sysmex, grants from GSK. Dr. Goto reports grants and personal fees from Eli Lilly, grants and personal fees from Chugai, grants and personal fees from Taiho Pharmaceutical, personal fees from Boehringer Ingelheim, grants and personal fees from Pfizer, grants and personal fees from Novartis, personal fees from AstraZeneca, grants and personal fees from MSD, grants and personal fees from Guardant Health, grants and personal fees from Ono Pharmaceutical, grants from Kyorin, grants from Dai-ichi Sankyo, personal fees from Illumina. Dr. Yoshida reports grants from MSD, grants from Ono Pharmaceutical, grants from Bristol-Myers Squibb, during the conduct of the study; grants and personal fees from AstraZeneca, grants from Takeda, personal fees from Chugai, personal fees from Novartis, and personal fees from Abbvie. Dr. Okuma reports personal fees from AstraZeneca, personal fees from Boehringer Ingelheim, personal fees from Chugai, personal fees from Ono, personal fees from Ily Lilly, personal fees from Bristol Myers Squibb. Dr. Matsumoto reports grants from Hitachi, Ltd., grants from Hitachi High-Technologies, personal fees from Olympus, personal fees from AstraZeneca, personal fees from Novartis, and personal fees from COOK. Dr. Horinouchi reports grants and personal fees from BMS, grants and personal fees from MSD, grants and personal fees from Chugai, grants and personal fees from Taiho, grants and personal fees from Astra Zeneca, grants from Astellas, grants from Merck Serono, grants from Genomic Health, grants and personal fees from Lilly, grants and personal fees from Ono. The remaining authors declare no conflict of interest.

Ethics approval and consent to participate The study was approved by the Institutional Review Board of the National Cancer Center Hospital (No. 2015-355).

Consent for publication This manuscript contains no individual person's data.

Open Access This article is licensed under a Creative Commons Attribution 4.0 International License, which permits use, sharing, adaptation, distribution and reproduction in any medium or format, as long as you give appropriate credit to the original author(s) and the source, provide a link to the Creative Commons licence, and indicate if changes were made. The images or other third party material in this article are included in the article's Creative Commons licence, unless indicated otherwise in a credit line to the material. If material is not included in the article's Creative Commons licence and your intended use is not permitted by statutory regulation or exceeds the permitted use, you will need to obtain permission directly from the copyright holder. To view a copy of this licence, visit http://creativecommons.org/licenses/by/4.0/.

\section{References}

Aguiar PN Jr, De Mello RA, Hall P, Tadokoro H, Lima Lopes G (2017) PD-L1 expression as a predictive biomarker in advanced nonsmall-cell lung cancer: updated survival data. Immunotherapy 9:499-506

Ahn MJ, Yang J, Yu H, Saka H, Ramalingam S, Goto K, Kim SW, Yang L, Walding A, Oxnard GR (2016) 136O: Osimertinib combined with durvalumab in EGFR-mutant non-small cell lung cancer: results from the TATTON phase Ib trial. J Thoracic Oncol 11:S115

Berghoff AS, Bellosillo B, Caux C, de Langen A, Mazieres J, Normanno N, Preusser M, Provencio M, Rojo F, Wolf J, Zielinski CC (2019) Immune checkpoint inhibitor treatment in patients with oncogene- addicted non-small cell lung cancer (NSCLC): summary of a multidisciplinary round-table discussion. ESMO Open 4:e000498

Borghaei H, Paz-Ares L, Horn L, Spigel DR, Steins M, Ready NE, Chow LQ, Vokes EE, Felip E, Holgado E, Barlesi F, Kohlhaufl M, Arrieta O, Burgio MA, Fayette J, Lena H, Poddubskaya E, Gerber DE, Gettinger SN, Rudin CM, Rizvi N, Crino L, Blumenschein GR Jr, Antonia SJ, Dorange C, Harbison CT, Graf Finckenstein F, Brahmer JR (2015) Nivolumab versus docetaxel in advanced nonsquamous non-small-cell lung cancer. N Engl J Med 373:1627-1639

Brahmer J, Reckamp KL, Baas P, Crino L, Eberhardt WE, Poddubskaya E, Antonia S, Pluzanski A, Vokes EE, Holgado E, Waterhouse D, Ready N, Gainor J, Aren Frontera O, Havel L, Steins M, Garassino MC, Aerts JG, Domine M, Paz-Ares L, Reck M, Baudelet C, Harbison CT, Lestini B, Spigel DR (2015) Nivolumab versus docetaxel in advanced squamous-cell non-small-cell lung cancer. N Engl J Med 373:123-135

Bylicki O, Paleiron N, Margery J, Guisier F, Vergnenegre A, Robinet G, Auliac JB, Gervais R, Chouaid C (2017) Targeting the PD-1/ PD-L1 immune checkpoint in EGFR-mutated or ALK-translocated non-small-cell lung cancer. Target Oncol 12:563-569 
Fehrenbacher L, Spira A, Ballinger M, Kowanetz M, Vansteenkiste J, Mazieres J, Park K, Smith D, Artal-Cortes A, Lewanski C, Braiteh F, Waterkamp D, He P, Zou W, Chen DS, Yi J, Sandler A, Rittmeyer A (2016) Atezolizumab versus docetaxel for patients with previously treated non-small-cell lung cancer (POPLAR): a multicentre, open-label, phase 2 randomised controlled trial. The Lancet 387:1837-1846

Gainor JF, Shaw AT, Sequist LV, Fu X, Azzoli CG, Piotrowska Z, Huynh TG, Zhao L, Fulton L, Schultz KR, Howe E, Farago AF, Sullivan RJ, Stone JR, Digumarthy S, Moran T, Hata AN, Yagi Y, Yeap BY, Engelman JA, Mino-Kenudson M (2016) EGFR Mutations and ALK rearrangements are associated with low response rates to PD-1 pathway blockade in non-small cell lung cancer: a retrospective analysis. Clin Cancer Res 22:4585-4593

Garon EB, Rizvi NA, Hui R, Leighl N, Balmanoukian AS, Eder JP, Patnaik A, Aggarwal C, Gubens M, Horn L, Carcereny E, Ahn MJ, Felip E, Lee JS, Hellmann MD, Hamid O, Goldman JW, Soria JC, Dolled-Filhart M, Rutledge RZ, Zhang J, Lunceford JK, Rangwala R, Lubiniecki GM, Roach C, Emancipator K, Gandhi L, Investigators K (2015) Pembrolizumab for the treatment of non-small-cell lung cancer. N Engl J Med 372:2018-2028

Herbst RS, Baas P, Kim D-W, Felip E, Pérez-Gracia JL, Han J-Y, Molina J, Kim J-H, Arvis CD, Ahn M-J, Majem M, Fidler MJ, de Castro G, Garrido M, Lubiniecki GM, Shentu Y, Im E, DolledFilhart M, Garon EB (2016) Pembrolizumab versus docetaxel for previously treated, PD-L1-positive, advanced non-small-cell lung cancer (KEYNOTE-010): a randomised controlled trial. The Lancet 387:1540-1550

Herbst RS, Soria JC, Kowanetz M, Fine GD, Hamid O, Gordon MS, Sosman JA, McDermott DF, Powderly JD, Gettinger SN, Kohrt HE, Horn L, Lawrence DP, Rost S, Leabman M, Xiao Y, Mokatrin A, Koeppen H, Hegde PS, Mellman I, Chen DS, Hodi FS (2014) Predictive correlates of response to the anti-PD-L1 antibody MPDL3280A in cancer patients. Nature 515:563-567

Kaira K, Kagamu H (2019) Drastic response of re-challenge of EGFRTKIs immediately after nivolumab therapy in EGFR-TKI-resistant patients. J Thorac Oncol 14:e135-e136

Lee CK, Man J, Lord S, Cooper W, Links M, Gebski V, Herbst RS, Gralla RJ, Mok T, Yang JC (2018) Clinical and molecular characteristics associated with survival among patients treated with checkpoint inhibitors for advanced non-small cell lung carcinoma: a systematic review and meta-analysis. JAMA oncology 4:210-216

Lisberg A, Cummings A, Goldman JW, Bornazyan K, Reese N, Wang T, Coluzzi P, Ledezma B, Mendenhall M, Hunt J, Wolf B, Jones B, Madrigal J, Horton J, Spiegel M, Carroll J, Gukasyan J, Williams T, Sauer L, Wells C, Hardy A, Linares P, Lim C, Ma L, Adame C, Garon EB (2018) A phase II study of pembrolizumab in EGFR-mutant, PD-L1+, tyrosine kinase inhibitor naive patients with advanced NSCLC. J Thorac Oncol 13:1138-1145

Mok TSK, Wu Y-L, Kudaba I, Kowalski DM, Cho BC, Turna HZ, Castro G, Srimuninnimit V, Laktionov KK, Bondarenko I, Kubota K, Lubiniecki GM, Zhang J, Kush D, Lopes G, Adamchuk G, Ahn M-J, Alexandru A, Altundag O, Alyasova A, Andrusenko O, Aoe K, Araujo A, Aren O, Arrieta Rodriguez O, Ativitavas T, Avendano O, Barata F, Barrios CH, Beato C, Bergstrom P, Betticher D, Bolotina L, Bondarenko I, Botha M, Buddu S, Caglevic C, Cardona A, Castro G, Castro H, Cay Senler F, Cerny CAS, Cesas A, Chan G-C, Chang J, Chen G, Chen X, Cheng S, Cheng Y, Cherciu N, Chiu C-H, Cho BC, Cicenas S, Ciurescu D, Cohen G, Costa MA, Danchaivijitr P, De Angelis F, de Azevedo SJ, Dediu M, Deliverski T, De Marchi PRM, de The Bustamante Valles F, Ding Z, Doganov B, Dreosti L, Duarte R, Edusma-Dy R, Emelyanov S, Erman M, Fan Y, Fein L, Feng J, Fenton D, Fernandes G, Ferreira C, Franke FA, Freitas H, Fujisaka Y, Galindo H, Galvez
C, Ganea D, Gil N, Girotto G, Goker E, Goksel T, Gomez Aubin G, Gomez Wolff L, Griph H, Gumus M, Hall J, Hart G, Havel L, He J, He Y, Hernandez Hernandez C, Hespanhol V, Hirashima T, Ho CMJ, Horiike A, Hosomi Y, Hotta K, Hou M, How SH, Hsia T-C, Hu Y, Ichiki M, Imamura F, Ivashchuk O, Iwamoto Y, Jaal J, Jassem J, Jordaan C, Juergens RA, Kaen D, Kalinka-Warzocha E, Karaseva N, Karaszewska B, Kazarnowicz A, Kasahara K, Katakami N, Kato T, Kawaguchi T, Kim JH, Kishi K, Kolek V, Koleva M, Kolman P, Koubkova L, Kowalyszyn R, Kowalski D, Koynov K, Ksienski D, Kubota K, Kudaba I, Kurata T, Kuusk G, Kuzina L, Laczo I, Ladrera GEI, Laktionov K, Landers G, Lazarev S, Lerzo G, Lesniewski Kmak K, Li W, Liam CK, Lifirenko I, Lipatov O, Liu X, Liu Z, Lo SH, Lopes V, Lopez K, Lu S, Martinengo G, Mas L, Matrosova M, Micheva R, Milanova Z, Miron L, Mok T, Molina M, Murakami S, Nakahara Y, Nguyen TQ, Nishimura T, Ochsenbein A, Ohira T, Ohman R, Ong CK, Ostoros G, Ouyang X, Ovchinnikova E, Ozyilkan O, Petruzelka L, Pham XD, Picon P, Piko B, Poltoratsky A, Ponomarova O, Popelkova P, Purkalne G, Qin S, Ramlau R, Rappaport B, Rey F, Richardet E, Roubec J, Ruff P, Rusyn A, Saka H, Salas J, Sandoval M, Santos L, Sawa T, Seetalarom K, Seker M, Seki N, Seolwane F, Shepherd L, Shevnya S, Shimada AK, Shparyk Y, Sinielnikov I, Sirbu D, Smaletz O, Soares JPH, Sookprasert A, Speranza G, Srimuninnimit V, Sriuranpong V, Stara Z, Su W-C, Sugawara S, Szpak W, Takahashi K, Takigawa N, Tanaka H, Tan Chun Bing J, Tang Q, Taranov P, Tejada H, Tho LM, Torii Y, Trukhyn D, Turdean M, Turna H, Ursol G, Vanasek J, Varela M, Vallejo M, Vera L, Victorino A-P, Vlasek T, Vynnychenko I, Wang B, Wang J, Wang K, Wu Y, Yamada K, Yang C-H, Yokoyama T, Yokoyama T, Yoshioka H, Yumuk F, Zambrano A, Zarba JJ, Zarubenkov O, Zemaitis M, Zhang L, Zhang L, Zhang X, Zhao J, Zhou C, Zhou J, Zhou Q, Zippelius A (2019) Pembrolizumab versus chemotherapy for previously untreated, PD-L1-expressing, locally advanced or metastatic non-small-cell lung cancer (KEYNOTE-042): a randomised, open-label, controlled, phase 3 trial. The Lancet 393:1819-1830

Reck M, Rodriguez-Abreu D, Robinson AG, Hui R, Csoszi T, Fulop A, Gottfried M, Peled N, Tafreshi A, Cuffe S, O'Brien M, Rao S, Hotta K, Leiby MA, Lubiniecki GM, Shentu Y, Rangwala R, Brahmer JR, Investigators K (2016) Pembrolizumab versus chemotherapy for PD-L1-positive non-small-cell lung cancer. N Engl J Med 375:1823-1833

Rittmeyer A, Barlesi F, Waterkamp D, Park K, Ciardiello F, von Pawel J, Gadgeel SM, Hida T, Kowalski DM, Dols MC, Cortinovis DL, Leach J, Polikoff J, Barrios C, Kabbinavar F, Frontera OA, De Marinis F, Turna H, Lee J-S, Ballinger M, Kowanetz M, He P, Chen DS, Sandler A, Gandara DR (2017) Atezolizumab versus docetaxel in patients with previously treated non-small-cell lung cancer (OAK): a phase 3, open-label, multicentre randomised controlled trial. The Lancet 389:255-265

Santambrogio L, Rammensee HG (2019) Contribution of the plasma and lymph degradome and peptidome to the MHC ligandome. Immunogenetics 71:203-216

Schoenfeld AJ, Arbour KC, Rizvi H, Iqbal AN, Gadgeel SM, Girshman J, Kris MG, Riely GJ, Yu HA, Hellmann MD (2019) Severe immune-related adverse events are common with sequential PD-(L)1 blockade and osimertinib. Ann Oncol 30:839-844

Socinski MA, Jotte RM, Cappuzzo F, Orlandi F, Stroyakovskiy D, Nogami N, Rodriguez-Abreu D, Moro-Sibilot D, Thomas CA, Barlesi F, Finley G, Kelsch C, Lee A, Coleman S, Deng Y, Shen Y, Kowanetz M, Lopez-Chavez A, Sandler A, Reck M, Group IMS (2018) Atezolizumab for First-Line Treatment of Metastatic Nonsquamous NSCLC. N Engl J Med 378:2288-2301

Publisher's Note Springer Nature remains neutral with regard to jurisdictional claims in published maps and institutional affiliations. 